\title{
Comparison of newer colonoscopy devices with standard forward viewing (SFV) high definition colonoscopies in daily practice
}

\author{
Martin Geyer ${ }^{*}$, Dominik J. Leiner ${ }^{2}$ and Fridolin Bannwart ${ }^{3}$ \\ ${ }^{1}$ Gastroenterologie Baden-Wettingen, Landstr. 166, CH-5430 Wettingen, Switzerland \\ ${ }^{2}$ LMU Munich, Department of Media and Communication, Oettingenstr. 67, D-80538 Munich, Germany \\ ${ }^{3}$ Medica Laboratories, institute of pathology, Hottingerstrasse 9/11, CH-8024; CH-8024 Zürich, Switzerland
}

\begin{abstract}
For years efforts have been made to improve the quality of colonoscopy. Cap assisted colonoscopy has shown in some studies to increase the adenoma detection rate $(\mathrm{ADR})$ as did full-spectrum colonoscopies $\left(\mathrm{FUSE}^{\circledR}\right)$ with $330^{\circ}$ angle, showing by initial studies a significantly lower adenoma miss rate and higher ADR. Subsequent FUSE $^{\circledR}$ studies were unable to confirm these results. Our practice-based, randomized study compares the efficiency, i.e. ADR, of the relatively inexpensive cap assisted, the FUSE ${ }^{\circledR}$ and standard forward-viewing (SFV) colonoscopy.

From March 2015 through February 2017 (phase A) patients referred for ambulant colonoscopy were randomly allocated to either colonoscopy with high definition SFV Pentax i10 (n=934) or FUSE ${ }^{\circledR}$ instruments ( $\left.=1044\right)$. From March 2017 through September 2019 (phase B) patients were systematically allocated to the colonoscopies, and the additional Endocuff ${ }^{\circledR}$ was used for the Pentax i10 instruments $\left(\mathrm{n}_{\text {Pentax }}=750, \mathrm{n}_{\mathrm{FUSE}}=1,386\right.$ ). All procedures were performed by one experienced endoscopist.

Baseline characteristics of the 1,978 (phase A) and 2,136 (phase B) patients were similar between the respective groups; remaining deviations were controlled for by regression models. Mean age was 62.9 years $(\mathrm{SD}=11.6$ ), half were male (50.5\%), BBPS (Boston Bowel Preparation Scale) score was 7.29 (SD=0.86). 38.2\% were screening, $59.5 \%$ surveillance, the remaining diagnostic colonoscopies. Ileum intubation rate was $98 \%$. Patients were sedated with Propofol (mean dose overall 189 mg; $\mathrm{SD}=107 \mathrm{mg}$ ), significantly less with Endocuff ${ }^{\circledR}(166 \mathrm{mg} ; \mathrm{SD}=67 \mathrm{mg}, \mathrm{CI}=161-171 \mathrm{mg})$. Average time to ileum was $5.6 \mathrm{minutes}$ with no significant (n.s.) difference between different devices. Withdrawal time was significantly faster with $\mathrm{FUSE}{ }^{\circledR}$ than with $\operatorname{Pentax}^{\circledR}$ in phase $\mathrm{A}\left(\mathrm{t}_{\mathrm{F}}=16.5\right.$ min., $\mathrm{t}_{\mathrm{P}}=18.1$ min, $\left.\mathrm{p}<0.001\right)$ and significantly faster with Endocuff ${ }^{\circledR}$ than with FUSE ${ }^{\circledR}$ in phase B ( $t_{\mathrm{F}}=14.4$ min., $\left.t_{\mathrm{F}}=15.8 \mathrm{~min}, \mathrm{p}<0.001\right)$. Multivariate analysis showed male sex, diabetes and age to be significant risk factors for more adenomas. ADR was 52\%/49\% for $\mathrm{FUSE}^{\circledR}$ (phase A/B), and 54\%/50\% for Pentax (differences are not statistically significant on $\alpha=5 \%$ level, n.s.). Adenoma identified per colonoscopy (APC) were 1.1/1.0 with FUSE ${ }^{\circledR}$ and 1.2/1.1 with Pentax (n.s.). The overall number of all polyps per colonoscopy (PPC) were 1.8/1.9 (FUSE $^{\circledR}$ ) and 1.9/1.7 (Pentax, n.s.). 81\% of the polyps were below $5 \mathrm{~mm}$ of size and only $5 \%$ were $10 \mathrm{~mm}$ or larger. $49 \%$ were tubular adenomas, $20 \%$ were serrated adenomas. In $0.61 \%$ a carcinoma was diagnosed.
\end{abstract}

Conclusion: In a collective of 4114 patients randomly or systematically assigned to 3 different types of colonoscopies neither FUSE ${ }^{\circledR}$ nor Endocuff ${ }^{\circledR}$ significantly increases the adenoma detection rate (ADR). At present, no further benefit can be expected from new technology. Key factor for a high ADR seems to be long withdrawal times (e.g. 14 up to 18 min in SFV). With FUSE ${ }^{\circledR}$ and Endocuff ${ }^{\circledR}$ endoscopy times (withdrawal) decreased significantly.

\section{Introduction}

Quality of colonoscopy has been established as key factor for successful colorectal screening programs. Cap assisted colonoscopy has been shown in some studies to increase the adenoma detection rate (ADR). Full-spectrum colonoscopies $\left(\mathrm{FUSE}^{\star}\right.$ ) with $330^{\circ}$ angle of view was the first wide angle endoscopy system reaching the market, initially showing significant lower adenoma miss rate and higher ADR. Subsequent FUSE ${ }^{\oplus}$ studies however failed to confirm these findings. Our practice-based, to our knowledge largest single-investigator study compares performance, especially ADR of the relatively inexpensive cap assisted, the FUSE $^{\oplus}$ and standard high definition (HD) SFV colonoscopy.

\section{Method}

From March 2015 through February 2017 (phase A) patients referred for ambulant colonoscopy in a private Swiss gastroenterologist's practice were alternatingly allocated to one of the two endoscopy theatres. One equipped with a FUSE ${ }^{\circledast}$ endoscopy system from Endochoice (later: Boston Scientific, $n_{A / F U S E}=1044$ examinations), the other with an EPKi Processor and Pentax $i 10$ colonoscopes $\left(n_{A}\right.$ ${ }_{P e n t a x}=934$ examinations). In March 2017 a second doctor joined the practice, but did not contribute to the study. These organizational changes required randomization to be switched from per-patient alternation to per-day alternation in phase B from March 2017 through September 2019. In phase B the FUSE $^{\infty}$ system was unchanged $\left(n_{B /}\right.$ ${ }_{\text {FUSE }}=1386$ examinations), while the Pentax $i 10$ colonoscopes were

*Correspondence to: Martin Geyer, Gastroenterologie Baden-Wettingen, Landstr. 166, CH-5430 Wettingen, Switzerland, Tel: 0041562272 92; E-Mail: geyer@gastro-bw.ch

Key words: full-spectrum colonoscopies, adenoma detection rate, Ileum intubation rate

Received: March 30, 2020; Accepted: April 17, 2020; Published: April 20, 2020 
additionally equipped with Endocuff $\left(n_{B / E n d o c u f f}=750\right.$ examinations). Patients with contraindication against Endocuff (known or found diverticular stenosis) were excluded from the study $\left(n_{B / \text { removed }}=127\right)$. Patients were given their appointments to any free slot throughout the week without stratification. The study and data analysis was consented by the ethical committee EKNZ Ethikkommission Nordwest- und Zentralschweiz (Project-ID 2019-01643).

All procedures were performed by one experienced endoscopist (board certified 2004) under nurse assisted propofol sedation (NAPS).

Baseline characteristics: age, sex, BMI, smoking habits, diabetes as well as quality of bowel preparation (measured by BBPS score) and indication for colonoscopy (screening, surveillance, diagnostic, such as diarrhoea, bleeding, persistent abdominal pain) were assessed. Amount of sedatives, other medications given during endoscopy (e.g. Buscopan $^{\circledR}$ ) and time for the endoscopy e.g. time to ileum, retraction time (pullback time minus intervention time) and time for intervention were measured by the assistant with a stopwatch. These parameters, polyp counts, size and their localisation (entered in a table and to an anatomical scheme), and satisfaction for all parts of the examination (bowel preparation and overall satisfaction) were real time entered to the database by a tablet computer (Figure 1). The data entry was done coded. Only the main investigator could subdue each single patient. Statistics were done with a professional statistics, the co-author Dr. Leiner. Under the assumption of a $10 \%$ higher adenoma detection rate in the FUSE group (historical data showed $11 \%$ more polyps detected with FUSE in comparison to standard colonoscopy according to congress abstract data from Blair S. et al.) at least 774 patients would be required in phase A to observe a significant effect (accepted alpha error $\alpha=0.05$, $t$-tests and $\mathrm{chi}^{2}$ tests) with a statistically power of $\beta \geq 0.8$. We expected a polyp detection rate of $50 \%$ with $\mathrm{FUSE}^{\oplus}$, compared to $40 \%$ with standard high definition colonoscopy. The study's primary outcome was the number of excised polyps, their size, localization and histology. Secondary outcomes were endoscopy times (time to coecum, retraction time), dose of sedation, comedication, and overall satisfaction with the colonoscopy.

Depending on the variable and the selection of the compared groups, either $\mathrm{chi}^{2}$ tests or $t$-tests have been used. Linear multiple regression models have been calculated to control for potential confounders, especially in phase B.

\section{Results}

Baseline characteristics of the 1,978 (phase A) and 2,136 (phase B) patients were similar between the respective groups (Table 1). Yet, dayto-day rotation in phase $\mathrm{B}$, compared to patient-to-patient rotation in phase A, resulted in some statistically significant baseline deviations in phase B. With change of the bowel preparation over time (from Moviprep ${ }^{\star}$ to Eziclen ${ }^{\circ}$ ) the cleaning became better with a BBPS score in phase B for FUSE ${ }^{\oplus}$ of 7.4 (CI 7.4-7.5) and for Pentax with Endocuff of 7.3 (CI 7.3-7.4) in comparison to Phase A with 7.2 (CI 7.2-7.3) and 7.1 (CI 7.1-7.2) respectively. One third were screening, almost two thirds surveillance, and 2-4\% diagnostic colonoscopies.

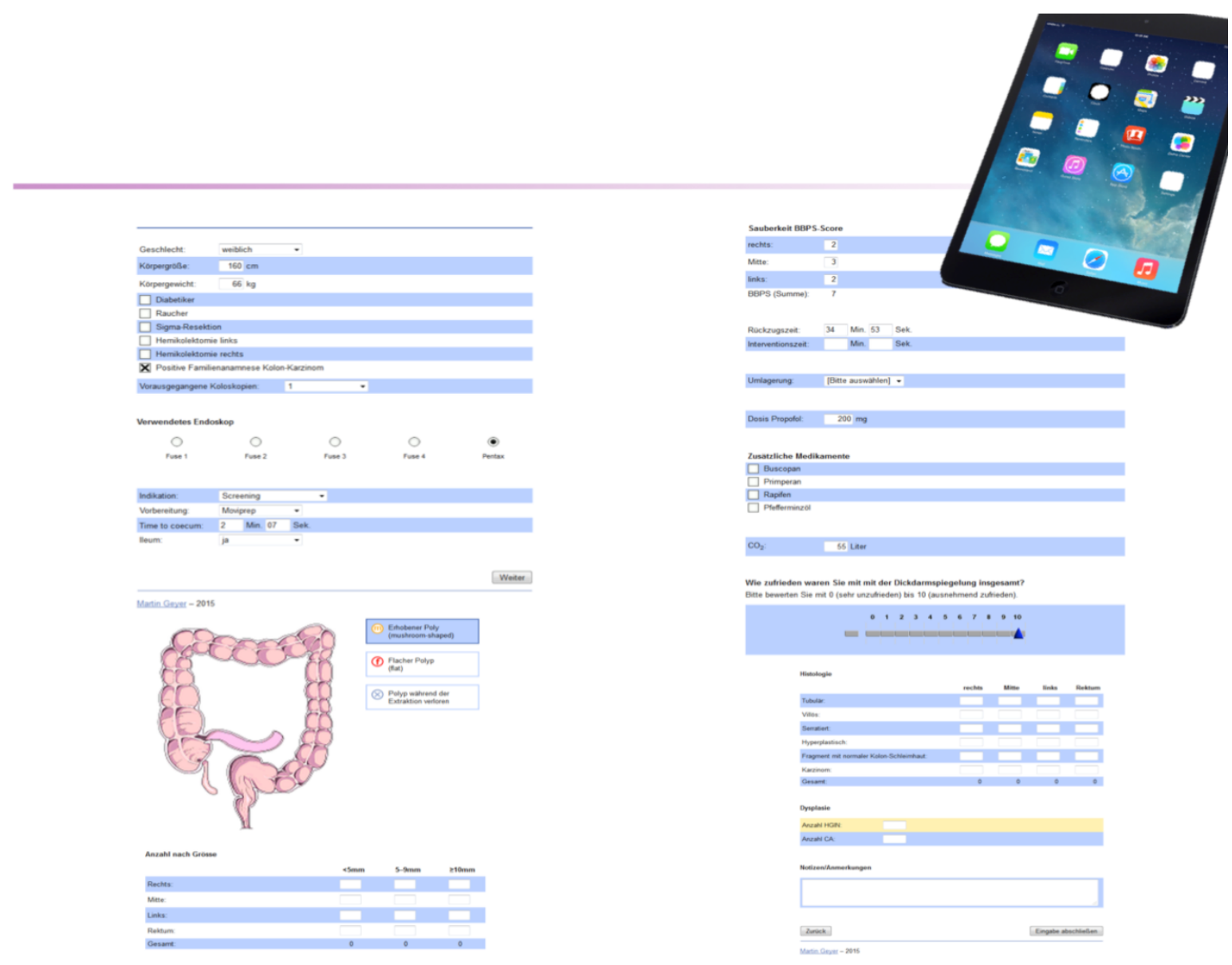

Figure 1. Baseline characteristics in real time entered to the database by a tablet computer. 
To control for random variation and systematic biases in the baseline characteristics (Table 1) all differences were tested in linear multiple regression models employing the colonoscopy device as binary dummy variable, and week day, gender, age, BMI, diabetes, smoker, previous colorectal operations, family history, BBPS, and indication for example screening to explain the respective outcome variable. One of the regressions, $\mathrm{ADR}$ in phase $\mathrm{A}$, is given as example (Table 2). The data confirms well-known risk factors such as gender, age as well as absence of a previous colorectal resection surgery.

In clear contrast to our hypothesis we did not observe significant effects by the colonoscopy device (significant regression coefficient) regarding the primary outcome variables. The outcomes were nearly the same for the devices within each phase (Table 3).
At least one adenoma was found in 2109 of 4114 colonoscopies, accounting for an overall adenoma detection rate (ADR) of $51 \%$. On average 1.1 adenoma were found per colonoscopy. Four out of five polyps (81\%) were smaller than $5 \mathrm{~mm}, 5 \%$ were $10 \mathrm{~mm}$ or larger. $95 \%$ were flat, $3.2 \%$ pedunculated, $1.8 \%$ of the polyps $(n=136$ of 7508) could not be extracted and examined histologically with no significant differences by device. One third (35\%) were right sided and one third located in the transverse colon (32\%). Histology identified $49 \%$ as tubular adenomas, $20 \%$ were serrated adenomas (SSA), $14 \%$ hyperplastic polyps, and $15 \%$ turned out not to be adenomatous (optical over diagnosis). 25 carcinomas $(0.61 \%)$ were identified. Table 3 reports two significant differences, yet given an overall number of 34 tests for significance $(\alpha=0.05)$, these two differences are likely false positives caused by alpha error inflation.

Table 1. Baseline characteristics

\begin{tabular}{|c|c|c|c|c|}
\hline \multirow[b]{2}{*}{ Colonoscopy device } & \multicolumn{2}{|l|}{\begin{tabular}{|l} 
Phase A \\
$(02 / 2015$ - 02/2017)
\end{tabular}} & \multicolumn{2}{|l|}{$\begin{array}{l}\text { Phase B } \\
(03 / 2017-09 / 2019)\end{array}$} \\
\hline & Pentax i 10 & FUSE® & FUSE® & Pentax i 10 plus Endocuff ${ }^{\circledR}$ \\
\hline Sample (n) & 934 & 1,044 & 1,386 & 750 \\
\hline Gender & q $49.9 \%$ & q $48.6 \%$ & + $49.1 \%$ & ㅇ $51.1 \%$ \\
\hline Age & 63.3 (CI 62.4-64.0) & 62.9 (CI 62.2-63.6) & 63.0 (CI 62.3-63.6) & 61.2 (CI 61.2-62.9) \\
\hline BMI & 25.9 (CI 25.5-26.2) & 25.6 (CI 25.3-25.8) & 25.6 (CI 25.4-25.9) & 26.0 (CI 25.6-26.3) \\
\hline Smoker & $7.8 \%$ & $6.9 \%$ & $7.0 \%$ & $10.7 \%^{1}$ \\
\hline Diabetics & $3.6 \%$ & $2.8 \%$ & $2.8 \%$ & $5.3 \%^{1}$ \\
\hline $\begin{array}{l}\text { Indication }^{2} \\
\text { Screening } \\
\text { Surveillance } \\
\text { Diagnostic }\end{array}$ & $\begin{array}{l}33.9 \% \\
63.7 \% \\
2.3 \%\end{array}$ & $\begin{array}{c}39.6 \% \\
58.9 \% \\
1.6 \%\end{array}$ & $\begin{array}{l}37.2 \% \\
60.9 \% \\
2.6 \% \\
\end{array}$ & $\begin{array}{l}43.6 \% \\
51.7 \% \\
2.7 \% \\
\end{array}$ \\
\hline BBPS & 7.1 (CI 7.1-7.2) & $7.2($ CI 7.2-7.3) & 7.4 (CI 7.4-7.5) & $7.3(\text { CI } 7.3-7.4)^{3}$ \\
\hline Ileum intubation & $99.1 \%$ & $98.1 \%^{4}$ & $98.2 \%$ & $98.4 \%$ \\
\hline $\begin{array}{l}\text { Satisfaction overall } \\
(0 \text { to } 10)\end{array}$ & 9.5 (CI 9.4-9.6) & 9.5 (CI 9.3-9.6) & 9.8 (CI 9.8-9.9) & $9.5(9.4-9.5)^{5}$ \\
\hline Propofol (mg) & 200 (CI 194-205) & 202 (CI 193-212) & 185 (CI 181-189) & $166\left(\right.$ CI 161-171) ${ }^{6}$ \\
\hline \multicolumn{5}{|c|}{$\begin{array}{l}\text { Confidence intervals }(\mathrm{CI}) \text { for means are specified for } 95 \% \text { confidence }(\alpha=0.05) \text {. } \\
\text { 1: phase B significant difference for smokers }(\mathrm{p}<0.01) \text { and diabetics }(\mathrm{p}<0.01) \\
\text { 2: significant differences for indication in phases A and B }(\mathrm{p}<0.05) \\
\text { 3: BBPS statistically significant better over time, and different in phase } \mathrm{B}(\mathrm{p}<0.001) \\
\text { 4: Ileum intubation rate was higher for SFV in phase A }(\mathrm{p}<0.05) \\
\text { 5: In phase B the patients assigned to FUSE } \mathbb{B} \text { reported a better overall satisfaction }(\mathrm{p}<0.001) \text {. This, like other baseline differences, is likely a systematic bias caused by day-to-day } \\
\text { rotation. } \\
\text { 6: significantly less sedation with Endocuff } \circledast(p<0.001)\end{array}$} \\
\hline
\end{tabular}

Table 2. Regression model explaining ADR in phase A

\begin{tabular}{|c|c|c|c|}
\hline Variable & Estimate (b) & Standard error & $\mathbf{p}$ \\
\hline (Intercept) & -2.593 & 0.585 & $<0.001 * * *$ \\
\hline day (Mon) & 0.010 & 0.164 & 0.950 \\
\hline day (Tue) & -0.232 & 0.173 & 0.180 \\
\hline day (Thu) & -0.121 & 0.162 & 0.460 \\
\hline day (Fri) & -0.098 & 0.169 & 0.560 \\
\hline gender (male) & 0.419 & 0.096 & $<0.001 * * *$ \\
\hline age (years) & 0.037 & 0.005 & $<0.001 * * *$ \\
\hline BMI & 0.015 & 0.011 & 0.150 \\
\hline risk: diabetes & 0.351 & 0.286 & 0.220 \\
\hline risk: smoker & 0.213 & 0.181 & 0.240 \\
\hline risk: colon operation & -0.832 & 0.286 & $0.004 * *$ \\
\hline risk: family history & -0.135 & 0.176 & 0.450 \\
\hline BBPS & 0.039 & 0.053 & 0.460 \\
\hline device: FUSE® & -0.146 & 0.096 & $0.130^{1}$ \\
\hline \multicolumn{4}{|c|}{$\begin{array}{l}\text { Binomial logistic regression on adenom detection (binary) per patient, phase A. Multiple imputation was applied to include } 72 \text { cases with missing data ( } \mathrm{n}=1978 \text { ). Overall ADR in phase } \\
\mathrm{A} \text { is } 53.0 \% \text {. } \\
{ }^{* *} \mathrm{p}<0.01, * * * \mathrm{p}<0.001 \text {. } \\
{ }^{1} \text { The central finding is that the device does not significantly explain ADR ( } \mathrm{p}>0.05 \text { ). In the tendency, a smaller ADR was observed with FUSE } \text { (in phase A, compared to Pentax } i \text { 10 (also } \\
\text { see Table 3). Odds ratio = exp }(-0.146)=0.864 \text {. }\end{array}$} \\
\hline
\end{tabular}


Table 3. Primary outcomes

\begin{tabular}{|c|c|c|c|c|}
\hline \multirow[b]{2}{*}{ Colonoscopy device } & \multicolumn{2}{|l|}{ Phase A } & \multicolumn{2}{|l|}{ Phase B } \\
\hline & Pentax i 10 & FUSE® & FUSE® & Pentax i 10 plus Endocuff ${ }^{\circledR}$ \\
\hline Adenoma Detection Rate (ADR) & $55.1 \%($ CI $52.0-58.3)$ & $52.1 \%($ CI $49.0-55.0)$ & $48.6 \%$ (CI 46.0-51.3) & $50.3 \%(\mathrm{CI} 46.7-53.9)$ \\
\hline Adenomas per colonscopy & $1.2($ CI $1.1-1.4)$ & 1.1 (CI 1.0-1.2) & $1.0($ CI $1.0-1.1)$ & 1.1 (CI 1.0-1.2) \\
\hline \multicolumn{5}{|l|}{ Polyp size } \\
\hline$<5 \mathrm{~mm}$ & 1.56 (CI 1.43-1.69) & 1.57 (CI $1.44-1.70)$ & 1.43 (CI $1.33-1.52)$ & 1.30 (CI $1.18-1.42)$ \\
\hline $5-9 \mathrm{~mm}$ & 0.25 (CI $0.20-0.31)$ & 0.25 (CI $0.19-0.30)$ & 0.25 (CI $0.22-0.29)$ & 0.28 (CI $0.23-0.33)$ \\
\hline$\geq 10 \mathrm{~mm}$ & 0.08 (CI 0.06-0.11) & 0.06 (CI 0.04-0.09) & 0.09 (CI 0.07-0.11) & 0.10 (CI 0.08-0.13) \\
\hline \multicolumn{5}{|l|}{ Shape } \\
\hline flat & 1.78 (CI 1.64-1.93) & 1.75 (CI 1.62-1.88) & 1.74 (CI 1.63-1.86) & 1.67 (CI 1.52-1.82) \\
\hline pedunculated & 0.07 (CI 0.05-0.09) & 0.07 (CI 0.05-0.09) & 0.05 (CI 0.04-0.07) & 0.05 (CI 0.03-0.07) \\
\hline \multicolumn{5}{|l|}{ Localization } \\
\hline right & 0.71 (CI $0.63-0.78)$ & 0.64 (CI $0.58-0.70)$ & 0.61 (CI 0.56-0.67) & 0.61 (CI $0.53-0.68)$ \\
\hline middle & 0.42 (CI $0.36-0.47)$ & 0.42 (CI $0.35-0.48)$ & 0.46 (CI $0.41-0.50)$ & 0.45 (CI $0.40-0.51)$ \\
\hline left & 0.63 (CI 0.56-0.71) & 0.64 (CI 0.56-0.72) & 0.55 (CI $0.50-0.60)$ & 0.53 (CI 0.47-0.60) \\
\hline rectum & 0.14 (CI 0.09-0.19) & 0.19 (CI 0.16-0.22) & 0.15 (CI $0.12-0.18)$ & $0.09(\text { CI } 0.06-0.12)^{1}$ \\
\hline \multicolumn{5}{|l|}{ Histology } \\
\hline Tubular & 0.83 (CI 0.73-0.92) & 0.78 (CI 0.71-0.86) & 0.76 (CI 0.69-0.83) & 0.73 (CI 0.64-0.83) \\
\hline Villous & 0.02 (CI $0.01-0.04)$ & 0.02 (CI 0.01-0.03) & 0.02 (CI $0.01-0.03)$ & 0.01 (CI $0.00-0.03)$ \\
\hline Serrated & 0.38 (CI $0.32-0.45)$ & 0.31 (CI $0.25-0.37)$ & 0.26 (CI 0.22-0.30) & 0.32 (CI 0.26-0.38) \\
\hline Hyperplastic & 0.20 (CI $0.16-0.23)$ & $0.27(\text { CI } 0.23-0.32)^{2}$ & 0.23 (CI 0.19-0.27) & 0.16 (CI 0.12-0.20) \\
\hline Normal mucosa & 0.22 (CI $0.18-0.25)$ & 0.27 (CI 0.22-0.32) & 0.24 (CI 0.21-0.27) & 0.25 (CI $0.20-0.30)$ \\
\hline Carcinoma & 0.007 (CI 0-0.007) & 0.007 (CI 0-0.009) & 0.006 (CI 0-0.002) & 0.003 (CI 0-0.004) \\
\hline
\end{tabular}

Table 4. Sedation and colonoscopy time

\begin{tabular}{|c|c|c|c|c|}
\hline & \multicolumn{2}{|l|}{ Phase A } & \multicolumn{2}{|l|}{ Phase B } \\
\hline & Pentax i 10 & FUSE® & FUSE® & Pentax i 10 plus Endocuff ${ }^{\circledR}$ \\
\hline Propofol dose (mg) & 200 (CI 194-207) & $202(193-212)$ & $185(181-189)$ & $166(161-171)^{1}$ \\
\hline Time to ileum (min.) & 5.4 (CI 5.2-5.6) & 5.7 (CI 4.9-6.5) & $5.4(\mathrm{CI} 4.7-6.1)$ & 6.0 (CI 5.6-6.4) \\
\hline Withdrawal (min.) & 18.6 (CI 17.7-18.5) & $16.5(\text { CI 16.1-16.8) })^{2}$ & 15.7 (CI 15.5-16.1) & $14.4(\text { CI } 14.0-14.7)^{3}$ \\
\hline Intervention (min.) & 3.3 (CI 3.0-3.7) & 3.3 (CI 2.9-3.6) & 3.2 (CI 2.9-3.4) & $2.7(\mathrm{CI} 2.3-3.1)^{4}$ \\
\hline \multicolumn{5}{|c|}{ 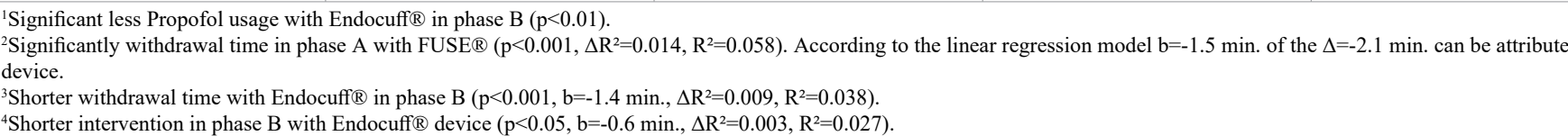 } \\
\hline
\end{tabular}

While no systematic differences were found between the devices, regarding adenoma detection, practical handling and aspects were looked at (secondary outcome variables). Differences were, again, tested for significance by multiple regression models. Firstly, nurses dosed significantly less Propofol in phase B when the colonoscopy was conducted with the Endocuff ${ }^{\infty}$ (Table 4, $\mathrm{b}=-12 \mathrm{ml}$ Propofol, $\mathrm{p}<0.01$, $\Delta \mathrm{R}^{2}=0.004$, comparing regression models without and with device, $\mathrm{R}^{2}=0.086$ ). Secondly, a shorter withdrawal time was required with FUSE ${ }^{\oplus}$ compared to SFV in phase A $(b=-1.5$ min., $p<0.001)$ and, both, shorter withdrawal $(b=-1.4 \mathrm{~min}, \mathrm{p}<0.01)$ and shorter intervention times $(b=-0.6$ Min., $p<0.05)$ when using Pentax with Endocuff in phase

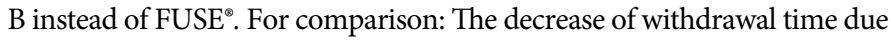
to better bowel preparation is about $-0.8 \mathrm{~min}$. $(\mathrm{p}<0.001)$ per BBPS point.

\section{Discussion}

This study compared FUSE ${ }^{\oplus}$, HD SFV colonoscopies with and without Endocuff regarding adenoma detection rate (ADR) and found no significant difference. Consequently, we reject the hypothesis that $\mathrm{FUSE}^{\bullet}$ would increase the ADR. One likely explanation for not finding differences in this regard in spite of wider angle of view of the FUSE instruments may be the very long average withdrawal times overall.
When using the SFV device average withdrawal time was 18.6 minutes ( $\mathrm{SD}=6.0 \mathrm{~min}$.), and still 14.4 minutes $(\mathrm{SD}=4.9 \mathrm{~min}$.) for the Endocuff device. Long inspection time of the colon clearly remains the key factor of quality for colonoscopy and a high ADR. Better imaging and additional tools like Cuffs may reduce the necessary time.

Strengths of our study are the large patient number and one investigator to minimize confounding factors. The standardized setting of a single site and an experienced investigator allowed comparison of available colonoscopes and Endocuff device in a unique manner. The results are mostly in a line with the study of Rex et al. [1]. Yet, while Rex et al. concluded that high definition is more important than angle of view, our study found no significant difference between wide angle and HD colonoscopies. Different to the initial tandem colonoscopy and simulated polyp study comparing the $\mathrm{FUSE}^{\oplus}$ system with standarddefinition (not HD) colonoscopies [2,3] which found that $\mathrm{FUSE}^{\bullet}$ was superior, in our study $\mathrm{FUSE}^{\oplus}$ was equally effective when it came to ADR. Similarly, a randomized multicentre Italian study conducted in the setting of the national CRC screening program was unable to demonstrate any statistically significant differences in ADR and advanced ADR between FUSE ${ }^{\oplus}$ and SFV in FIT (fecal immunochemical test)-positive individuals [4]. This study however was different to 
our study performed on a very specific population with an expected very high prevalence of neoplastic lesions due to FIT positivity. The endoscopists were likely to have maximized the diagnostic accuracy of each single technique to avoid relevant false-negative results. Not only in our study is the endoscopist's reputation [5] a factor pushing motivation to maximize ADR with whatever instrument. This is probabely even more important in a private practice than in an institution with several care providers. This and former studies do not exclude that in a certain setting (for example low level detectors) endoscopists may profit individually from one or the other assistance device or type of colonoscope.

Many studies show that an ADR of 50\% [6] to 69\% cannot be topped, because on this level most likely all present polyps are identified. Therefore, an advanced technique will have its difficulties to show superiority in what concerns ADR, especially if conducted by experienced endoscopists. Future studies on new techniques may take other factors besides ADR into account. In our study, for example, the necessary withdrawal time statistically decreased for FUSE ${ }^{\star}$ (minus 1.5 minutes) and for Endocuff (minus 1.4 minutes) without compromise on quality in what concerns ADR. This might be due to easier visualization of the mucosa due to wider angle of view or the tentacles stretching the folds and helping getting better sight. Relevant factors for daily routine (e.g. time saving, handling of the instrument, amount of sedatives, satisfaction of patients and doctors) have so far received little investigation. We conducted further statistical analyses that showed time gain with newer technique the longer they are used and the more experienced the endoscopist got. Our observation of 2.3 minutes time saving per colonoscopy might overestimate the gain per year, and might be valid for the first years only. Still, the Endocuff requires to our minds more than a hundred investigations to really get used to this device and perform at its best.

Individual skills and preferences may influence the choice of the endoscope or device. There may also be inter-individual differences in detection. Endocuff may be tried, as it is known to increase ADR especially for endoscopist with lower ADR [7]. It may also contribute to shorter endoscopy time and less sedation demand. These aspects could make strong arguments to use such additional devices, and shall be further investigated.
Limitations of our study were the uneven randomisation especially in phase $\mathrm{B}$ due to the practical organisation of the daily endoscopy program. The significant difference in some baseline characteristics (uneven distribution of smokers, diabetics and amelioration of BBPS over time) are limited and were statistically controlled for. The patient disposition was not deliberately influenced neither by nurses or the doctor. We observed no important deviations between the results with (regression) and without ( $t$-test on means) third variable control.

\section{Conclusion}

In a collective of 4114 patients randomly assigned to 3 different types of colonoscopies neither $\mathrm{FUSE}^{\circledR}$ nor Endocuff significantly increased the ADR. At present, if ADR reaches around 50\%, no further benefit can be expected from new technology. Key factor for a high ADR seems to be long withdrawal time and endoscopists experience. FUSE $^{\odot}$ and Endocuff show significantly shorter endoscopy times, Endocuff showed a small but significant decrease of sedative dose.

\section{References}

1. Rex DK, Repici A, Gross SA, Hassan C, Ponugoti PL, et al. (2018) High-definition colonoscopy versus Endocuff ${ }^{\mathbb{B}}$ versus EndoRings versus full-spectrum endoscopy for adenoma detection at colonoscopy: a multicenter randomized trial. Gastrointest Endosc 88: 335-344.e2. [Crossref]

2. Gralnek IM, Siersema PD, Halpern Z, Segol O, Melhem A, et al. (2014) Standard forward-viewing colonoscopy versus full-spectzrum endoscopy: an international, multicentre, randomised tandem colonoscopy trial. Lancet Oncol 15: 353-360. [Crossref]

3. Gralnek IM, Carr-Locke DL, Segol O, Santo E, et al. (2013) Comparision of standard forward-viewing mode versus ultrawide-viewing mode of a novel colonoscopy platform: a prospective, multicentre study in the detection of simulated polyps in an in vitro colon model. Gastrointest Endosc 77: 472-479.

4. Hassan C, Senore C, Radaelli F, De Pretis G, Sassatelli R, et al. (2017) Full-spectrum $\left(\mathrm{FUSE}^{\mathbb{Q}}\right.$ ) versus standard forward-viewing colonoscopy in an organised colorectal cancer screening programme. Gut 66: 1949-1955. [Crossref]

5. Abdul-Baki H, Schoen RE, Dean K, Rose S, Leffler DA, et al. (2015) Public reporting rate of colonoscopy quality is associated with an increase in endoscopist adenoma detection rate. Gastrointest Endosc 82: 676-682.

6. Corley DA, Levin TR, Christopher D (2014) Adenoma Detection Rate and Risk of Colorectal Cancer and Death. N Engl J Med 370: 1298-1306. [Crossref]

7. Rastogi A, Bansal A, Rao DS, Gupta N, Wani SB, et al. (2012) Higher adenoma detection rates with cap-assisted colonoscopy: a randomized controlled trial. Gut 61: $402-408$

Copyright: (C2020 Geyer M. This is an open-access article distributed under the terms of the Creative Commons Attribution License, which permits unrestricted use, distribution, and reproduction in any medium, provided the original author and source are credited. 